\title{
Letter
}

\section{Hypocalcaemia and Stridor: An Unusual Presentation of Acute Necrotizing Pancreatitis}

\author{
Naouel Guirat-Dhouib ${ }^{1,6}$, Fatma Derbali ${ }^{2,6}$, Afifa Charfi ${ }^{3,6}$, Lobna Aissa ${ }^{4}$, Zohra Sassi ${ }^{5}$, \\ Hammouda Taieb ${ }^{1}$, Ezzeddine Chouaibi ${ }^{1}$ \\ ${ }^{1}$ Department of Pediatrics, Regional Hospital of Sidi Bouzid, Sidi Bouzid, Tunisia \\ ${ }^{2}$ Internal Medicine Department, Regional Hospital of Sidi Bouzid, Sidi Bouzid, Tunisia \\ ${ }^{3}$ Department of Otolaryngology, Regional Hospital of Sidi Bouzid, Sidi Bouzid, Tunisia \\ ${ }^{4}$ Intensive Care Unit, Regional Hospital of Sidi Bouzid, Sidi Bouzid, Tunisia \\ ${ }^{5}$ Nephrology Department, Regional Hospital of Sidi Bouzid, Sidi Bouzid, Tunisia \\ ${ }^{6}$ Faculty of Medicine of Sousse, University of Sousse, Sousse, Tunisia
}

\section{Email address:}

nawel.guirat@yahoo.fr (N. Guirat-Dhouib), derbalifatma@yahoo.com (F. Derbali), afifa.charfi@rns.tn (A. Charfi), lobnaaissa@yahoo.fr (L. Aissa), zohrasassijallali@gmail.com (Z. Sassi), hammoudataieb@yahoo.fr (H. Taieb), ezedinechouaibi@topnet.tn (E. Chouaibi)

\section{To cite this article:}

Naouel Guirat-Dhouib, Fatma Derbali, Afifa. Charfi, Lobna. Aissa, Zohra Sassi, Hammouda. Taieb, Ezzeddine Chouaibi. Hypocalcaemia and Stridor: An Unusual Presentation of Acute Necrotizing Pancreatitis. International Journal of Biomedical Engineering and Clinical Science. Vol. 3, No. 6, 2017, pp. 78-80. doi: 10.11648/j.ijbecs.20170306.11

Received: May 11, 2017; Accepted: September 8, 2017; Published: November 1, 2017

\begin{abstract}
The differential diagnosis of stridor in the pediatric population is broad and should include hypocalcaemia with resultant laryngospasm. We present the case of a 10-year-old Tunisian girl, with no particular family or personal history, who presented with stridor secondary to profound hypocalcaemia. The diagnosis of acute pancreatitis was made after dosing systematically pancreatic amylases for elevation of blood sugar and glucosuria. Necrotizing pancreatitis was confirmed by abdominal CT scan.
\end{abstract}

Keywords: Stridor, Hypocalcaemia, Necrotizing pancreatitis, Child

\section{Introduction}

Pancreatitis is a significant cause of mortality and morbidity in the pediatric population. Nearly a quarter of children with acute pancreatitis develop a severe complication, and the mortality rate is approximately $4 \%$ despite significant advances in the treatment of this disease [1]. There are a few case reports of necrotizing pancreatitis in children [2,3]. From five large pediatric series in the United States [2], pancreatic necrosis was observed in only 3 out of 1014 children. Hypocalcaemia as a cause of stridor revealing an acute necrotizing pancreatitis is unusual.

\section{Case Report}

A 10-year-old Tunisian girl, admitted to intensive care unit for acute marked respiratory distress and stridor. She was born at full term, from non-sanguineous parents, following an uneventful pregnancy with a birth weight of $3 \mathrm{~kg}$ and a birth length of $50 \mathrm{~cm}$. Our patient did not have any family history of diabetes. No allergies or medication taking were reported. She had normal psychomotor development and vaccinations had been given on schedule with no previous hospitalizations. Her mother reported a preceding history rhinorrhea with fever two days earlier. At the time of presentation, her height was $130 \mathrm{~cm}$ : +0.2 standard deviation and her weight was $33 \mathrm{~kg}(+0.3$ standard deviation and body mass index was $\left.19.62 \mathrm{Kg} / \mathrm{m}^{2}\right)$. There was no evidence of dysmorphic features. The infant's temperature was $38^{\circ} \mathrm{C}$, oxygen saturation was $88 \%$ and her blood pressure was $100-70 \mathrm{mmHg}$. The heart rate was regular at 100 beats/min and the heart sounds were normal with no murmurs, gallops, or rubs. She was tachypneic, and her accessory muscles were joining in respiration. On auscultation 
of her chest, normal vesicular breath sounds were heard; there was no wheezing or rhonchus. Abdominal examination showed epigastric tenderness. The remainder of the physical examination was unremarkable. Results of an anterior chest $\mathrm{X}$-ray were normal. Hematology tests on admission revealed a total leukocyte count of $37.6 \mathrm{~K} / \mathrm{UL}$, hemoglobin level of 9.5 $\mathrm{g} / \mathrm{dL}$ and a platelet count of $120 \mathrm{~K} / \mathrm{ml}$. Her level of serum calcium was $1.55 \mathrm{mmol} / \mathrm{L}$. A repeat glucose test showed a high value of $15.57 \mathrm{mmol} / 1(283 \mathrm{mg} / \mathrm{dL})$. Serum amylase value was $737 \mathrm{UI} / \mathrm{L}$ (reference range $<86 \mathrm{UI} / \mathrm{L}$ ). Her levels of serum aspartate aminotransferase and alkaline phosphatases were normal. Renal function was compatible with acute renal failure. Her creatinine clearance test was normal $(20 \mathrm{ml} / \mathrm{min} /$ $1.73 \mathrm{~m}^{2}$ ). Abdominal ultrasonography evaluation was normal. Computed tomography with intravenous contrast was performed and revealed a lack of enhancement of the pancreas with necrosis. Parenteral nutrition was administered since admission. An intravenousre placement therapy with calcium chloride was given. Her calcium level returned to baseline after $20 \mathrm{~h}$ of calciumre placement therapy. Outcome was marked by aggravation of renal function leading to hemodialysis. The patient was died with multi organ failure.

\section{Discussion}

Acute necrotizing pancreatitis is a serious condition associated with high morbidity and mortality rates. Itis well described in adults [4], and diagnosed by a lack of enhancement of the pancreas on a Computed Tomography (CT) scan with intravenous contrast. However, there is very limited data in the pediatric literature regarding acute necrotizing pancreatitis. Acute necrotizing pancreatitis is a rare but severe condition that occurs in less than $1 \%$ of children with acute pancreatitis [5]. In contrast to adults, the causes of acute pancreatitis in children are more varied including biliary anomalies, inborn error of metabolism, drugs, traumas, and infections, metabolic and multisystem disorders [6]. However the data are limited regarding outcome. The initial presentation in our case presentation was atypical that of acute pancreatitis described in children. Our patient had a stridor without abdominal pain or vomiting. The diagnosis of acute pancreatitis was made after dosing systematically pancreatic enzymes for elevation of blood sugar and glucosuria. We observed leukocytosis with hypocalcaemia. In a large study with acute pancreatitis, these features have been shown to indicate severe pancreatitis [7]. Exact mechanism of hypocalcemia in acute pancreatitis is unknown. According to what has been reported [8-10], hypocalcemia during early stage could be explained by auto digestion of mesenteric fat by pancreatic enzymes and release of free fatty acids, which form calcium salts, transient hypoparathyroidism, and hypomagnesaemia. The lack of an accurate scoring system for pediatric acute pancreatitis could cause delays in appropriate clinical management and increase the risk of progressive life-threatening complications. Hyperglycemia and glycosuria commonly accompany episodes [11]. Vandana et al. [12] reported 48 among 176 studied children with pancreatitis. The occurrence of hyperglycemia was correlated with the severity of pancreatitis and could be explained either by impaired insulin secretion or peripheral insulin resistance [13]. Children who present acutely with respiratory distress and stridor are among the most frightening patients to manage in the pediatric emergency department. Pediatricians should consider obtaining blood pancreatic amylases in pediatric patients with stridor secondary to hypocalcaemia, especially in the context of hyperglycemia. Abdominal ultrasonography is frequently used as an initial diagnostic study for patients suffering from acute abdominal pain [14]. It can both diagnose acute pancreatitis and exclude gallstones as cause of pancreatitis. It has the advantages of low cost, ready availability, and easy portability for bedside application in very sick patients [15]. When adequately visualized, an inflamed pancreas is recognized as hypoechoic and enlarged because of parenchymal edema. In addition to excessive intestinal gas, ultrasound has limited capabilities in evaluating the presence and extent of necrosis, in detecting the full extent of pancreatic related fluid collections and in identifying gastrointestinal tract complications. Moreover, abdominal ultrasound is less accurate than Computed Tomography in delineating peripancreatic inflammation and detecting intrapancreatic necrosis. Computed Tomography has become the standard of choice and worldwide the most commonly used imaging modality for the initial evaluation and follow-up of patients with acute pancreatitis [16, 17]. Furthermore, CT is widely available, easily accessible in most institutions, less costly than magnetic resonance imaging, highly sensitive for the detection of gas bubbles and calcification, highly accurate, reproducible, and relatively easy to read by both radiologists and clinicians. We assessed Computed Tomography scan grading proposed by the United Kingdom guidelines in adults to confirm the diagnosis of pancreatitis [18]. The availability of new imaging modalities and noninvasive therapies has also changed clinical practice $[19,20]$. Our patient had a high severity index. Initial assessment of severity is one of the most important issues in the management of acute pancreatitis [21]. Aggressive intravenous fluid replacement is very important to treat fluid losses caused by third space shifts, vomiting, diaphoresis, and increased vascular permeability caused by inflammatory mediators. Clinically, the adequacy of fluid resuscitation should be monitored in terms of vital signs, urinary output, A second important consequence of hypovolemia is intestinal ischemia. Ischemia increases intestinal permeability to bacteria and endotoxins, an important cause of secondary pancreatic infection. Adequate pain management with opiate analgesics is important for treatment of severe pain associated with acute pancreatitis. Patient-controlled analgesia is often helpful for good pain control. However, monitoring of oxygenation while on high-dose opiate medications is necessary. Initial studies suggested that antibiotics were useful in preventing infection of necrosis, septic complications, and mortality in patients with acute pancreatitis; however, more recent, better-designed studies established that prophylactic antibiotics are not helpful. In the absence of infection. In our 
case study, outcome was severe leading to endocrine pancreatic insufficiency requiring insulin, acute renal failure and death [22].

\section{Conclusion}

Acute necrotizing pancreatitis is a rare and a serious condition occurring in all age groups, even in infants. Our report underlines that acute pancreatitis should be added to the list of uncommon manifestations of a stridor due to hypocalcaemia in elderly children. The screening of pancreatic enzymes is helpful for the diagnosis. The diagnosis of necrotizing pancreatitis is important since the morbidity associated with acute pancreatitis increases markedly when necrosis is present. Despite improvements in access to care, imaging and interventional techniques, acute pancreatitis continues to be associated with significant morbidity and mortality. Many treatment options are available for acute pancreatitis. Identification of patients with clinically severe $\mathrm{AP}$ is important as these patients may benefit from transfer to a specialized or intensive care unit, where they can receive aggressive fluid resuscitation and be closely monitored for the development of organ failure.

\section{References}

[1] De Banto J R, Goday P S, Pedroso M R, et al.: Acute pancreatitis in children. Am J Gastroenterol 2002, 97: 1726-1731.

[2] Lopez M J. The changing incidence of acute pancreatitis in children: a single- institution perspective. J Pediatr 2002, 140: 622-624.

[3] Park A J, Latif S U, Ahmad M U, Bultron G, Orabi AI, Bhandari $\mathrm{V}$, et al. A comparison of presentation and management trends in acute pancreatitis between infants/toddlers and older children. J Pediatr Gastroenterol Nutr 2010, 51: 167-170.

[4] Baron T H, Morgan D E. Acute necrotizing pancreatitis. N Engl J Med 1999, 340: 1412-1417.

[5] Whitcomb D C, Lowe ME. Pancreatitis: acute and chronic. In: Kleinman RE, Sanderson IR, Goulet O, et al., eds. Walker's pediatric gastrointestinal disease. Hamilton (ON): B C Decker Inc; 2008, 1213-1220.

[6] Husain SZ, Srinath AI. What's unique about acute pancreatitis in children: risk factors, diagnosis and management. Nat Rev Gastroenterol Hepatol. 2017 Mar 15. doi: 10.1038/nrgastro.2017.13.

[7] Peng T, Peng X, Huang M, Cui J, Zhang Y, Wu H, Wang C. Serum calcium as an indicator of persistent organ failure in acute pancreatitis. Am J Emerg Med. Doi: 10.1016/j. ajem. 2017.02.006.

[8] Condon J R, Ives D, Knight M J, Day J. The aetiology of hypocalcaemia in acute pancreatitis. Br J Surg 1975; 62: 115-8.

[9] McMahon MJ, Woodhead JS, Hayward RD. The nature of hypocalcaemia in acute pancreatitis. Br J Surg 1978; 65: 216-8. 15 .

[10] Ryzen E, Rude R K. Low intracellular magnesium in patients with acute pancreatitis and hypocalcemia. West J Med 1990; 152: $145-8$.

[11] Shenoy S D, Cody D, Rickett A B, Swift P G. Acute pancreatitis and its association with diabetes mellitus in children. J Pediatr Endocrinol Metab 2004, 17: 1667-1670.

[12] Vandana S. Raman, M D, Robert W. Loar, Venkat S. Renukuntla, MBBS, MPH, Krishna V. Hassan, MD, Douglas S. Fishman, MD, Mark A. Gilger, MD, and Rubina A. Heptulla, MD Hyperglycemia and Diabetes Mellitus in Children with Pancreatitis. J Pediatr 2011, 158: 612- 616.

[13] Qader SS, Ekelund M, Andersson R, Obermuller S, Salehi A. Acute pancreatitis, expression of inducible nitric oxide synthase and defective insulin secretion. Cell Tissue Res 2003, 313: $271-279$

[14] Merkle E M, Görich J. Imaging of acute pancreatitis. Eur Radiol 2002; 12: 1979-1992.

[15] Bennett G L, Hann LE. Pancreatic ultrasonography. Surg Clin North Am 2001; 81(2): 259-81.

[16] Bollen T L. Acute pancreatitis: international classification and nomenclature. Clin Radiol 2016; 71(2): 121-133.

[17] Thoeni R F. The revised Atlanta classification of acute pancreatitis: its importance for the radiologist and its effect on treatment. Radiology, 2012; 262(3): 751-764.

[18] UK Working Party on Acute Pancreatitis. UK guidelines for the management of acute pancreatitis. Gut 2005, 54 (Suppl 3): 1-9.

[19] Loveday B P, Srinivasa S, Vather R, et al. High quantity and variable quality of guidelines for acute pancreatitis: a systematic review. Am J Gastroenterol 2010; 105: 1466-76.

[20] Greenberg J A, Jonathan H, Bawazeer M, Marshall J, Friedrich J O., Nathens A, Coburn, N, May G R, Pearsall E, Mc Leod RS. Clinical practice guideline: management of acute pancreatitis. Can J Surg. 2016 Apr; 59(2): 128-140.

[21] Dupuis C S, Baptista V, Whalen G, Karam A R, Singh A, Wassef W, Kim Y H, Diagnosis and management of acute pancreatitis and its complications. Gastrointest Interv 2013; 2: $36-46$.

[22] Zavyalov T, Khotsyna Y, Tenner S. The role of antibiotics in the management of patients with acute necrotizing pancreatitis. Curr Infect Dis Rep 2010; 12(1): 13-8. 